
SCIENCE STUDENTS AND TEACHERS

Patrick Rousche, University of Illinois-Chicago

Michael Cho, University of Illinois-Chicago

Yang Dai, University of Illinois-Chicago

J Hetling, University of Illinois-Chicago

Hui Lu, University of Illinois-Chicago

jie liang, University of Illinois-Chicago

Susan McCormick, University of Illinois-Chicago

David Schneeweis, University of Illinois-Chicago

Richard Magin, University of Illinois-Chicago 


\section{A BioEngineering Summer Day Camp for High-School Science Students and Teachers}

\section{Abstract}

Fortunately, as a relative newcomer to undergraduate academic engineering circles, the field of Bioengineering has yet to become particularly prone to problems of student recruitment. However, at our institution, undergraduate engineering students are not formerly introduced to the field of Bioengineering until the sophomore year. Because of the broad nature of the field of Bioengineering, early exposure and education can be critical in helping students to accurately understand and ultimately choose exactly which discipline in Bioengineering for which they might be most well-suited. However, traditional colleges of engineering may be reluctant to modify an established and effective freshman core curriculum to allow for broad early bioengineering exposure. One supportive measure in lieu of revising an entrenched undergraduate core engineering curriculum is to provide bioengineering exposure to 9-12 high school students before they begin undergraduate training. To do this effectively also requires increased bioengineering knowledge in high school science teachers. To help foster an increased knowledge and understanding of Bioengineering among the grades 9-12 student group and their science teachers in a large metropolitan area, we developed a weeklong Bioengineering summer day camp program.

The typically intense, but short instructional sequences of the camp provide an ideal means for the introduction and immersion of 9-12 students and science teachers into bioengineering. Our camp had the following objectives: 1) To provide students with a hands-on Bioengineering experience. 2) To educate students about career opportunities in Bioengineering. 3) To create institutional/departmental name recognition among local students and science teachers. 4) To educate science teachers about important Bioengineering concepts. 5) To develop students' group communication and scientific presentation skills. 6) To develop students' ability to apply the scientific method and analyze data, and 7) To encourage family support of students' scientific pursuits. In this paper we review comparative assessment data from 3 successive years of offering the camp to local metropolitan area students.

\section{Introduction}

Bioengineering is a relatively modern discipline within engineering. Only a few academic institutions have bioengineering departments more than 15 years old. Broadly described as the intersection between biology and engineering, bioengineering (or its sister term biomedical engineering) encompasses a wide range of academic pursuits. Bioengineers investigate systems as small and specialized as mitochondria and as large and complex as the trillion cell network of the brain. Work in the field is incredibly diverse, ranging from the basic science of cell biomechanics and mobility to the development and application of clinical devices such as heart rate monitors or MRI machines. As a brash and bold upstart to 
undergraduate academic engineering circles, this exciting discipline has yet to become particularly prone to problems of student recruitment. However, at our institution, undergraduate engineering students are not formerly introduced to the field of Bioengineering until the sophomore year. Because of the broad nature of the field of Bioengineering, early exposure and education can be critical in helping students to accurately understand and ultimately choose exactly which discipline in Bioengineering for which they might be most well-suited. However, many colleges of engineering may be reluctant and/or simply unable to modify an established and effective freshman core curriculum to allow for broad early bioengineering exposure.

One alternative to revising an entrenched undergraduate core engineering curriculum is to provide bioengineering exposure to high school students before they begin undergraduate training. Such an approach is particularly appealing for our student body, $75 \%$ of whom come from the local metropolitan area. Early exposure for grades 9-12 students would help to strengthen and highlight bioengineering as a college major choice. In addition, it would introduce students to optimal preparatory coursework at a time when they can still modify their current class selections. Further, interaction with local 9-12 students might increase 'brand recognition' of our university name. Prior work suggests that students in grades 9-12 have been exposed to the essentials of math and science necessary for basic discussions of Bioengineering concepts (Openshaw et al., 1999). Unfortunately, there is little evidence that traditional 9-12 curriculums offer significant flexibility to easily include integrated discussions of both engineering and biology. One defining factor is likely the lack of bioengineering-related knowledge in secondary science school teachers. To help foster an increased knowledge and understanding of Bioengineering among the grades 9-12 student group and their science teachers, we developed a week-long Bioengineering summer camp program.

The 'summer camp' format has a long history as a non-threatening educational vehicle for introducing K-12 students to a variety of educational experiences. While originally implemented for instructions in the outdoor arts, summer camps available today span the gamut of activities from skateboarding to nursing. Summer camp is traditionally associated with enjoyable activities and when coupled with the integration of specialized academic matter, can become an excellent alternative to standard classroom educational techniques. The typically intense, but short sequences provide an ideal means for the introduction and immersion of K-12 students into areas that might not be so easily discussed in a traditional classroom setting (Malgorazata et al., 1999, McCoullough et al., 1994). Summer camp has also been used successfully as an academic 'recruiting tool' in nursing (Jaffe-Ruiz et al., 1989). To recruit potential bioengineering students, take advantage of the educational benefits, and expose 9-12 students and their science teachers to bioengineering, we designed a one week Bioengineering summer camp. The camp was designed for attendance by both science students and teachers with the following objectives:

1) To provide students with a hands-on Bioengineering experience

2) To educate students about career opportunities in Bioengineering

3) To create institutional/departmental name recognition among local students and science teachers 
4) To educate science teachers about important Bioengineering concepts

5) To develop students' group communication and scientific presentation skills

6) To develop students' ability to apply the scientific method and analyze data

7) To encourage family support of students' scientific pursuits

For three years now we have now successfully run a one-week summer session of the Experience Bioengineering Summer Camp for students and teachers in the Chicago metropolitan area.

III. Format

Each year the camp was scheduled over a 5 (years 1 and 2) or 6 (year 3) day period. Day 6 was added as a 'family day'. Activities were scheduled from Monday (Tuesday) through Friday (9 AM to 4:30 PM) and on Saturday (8:00 AM to 12:00PM). High-school students and science teachers spent the entire day on campus or at designated local biomedical industry facilities. In camp year one (CY1), senior students were targeted. In CY2 and CY3, sophomores and juniors were targeted. Each day began with a special-topics lecture in a mixed student/teacher setting. Lectures were typically followed by group tours of university or commercial medical/bioengineering facilities. A group lunch for all participants including the camp faculty was provided each day. Mid-week, a separate lunch was arranged for the high school teachers and university faculty alone. In CY1, students were assigned to a single laboratory to complete a project (a vote was used to try and match students to their preferred laboratory). In CY2 and CY3, students rotated throughout the laboratories in small working groups of 4-8 students. Teachers were not assigned to laboratories or groups. They were given a high degree of flexibility and encouraged to move from laboratory to laboratory to watch various stages of training and testing. They were encouraged to complete some of the laboratory exercises as desired. On the final day, all participants were surveyed to determine areas of expectations, outcomes, strengths, and weaknesses within the camp format. Only in camp year 3 were surveys were given on the first and final day.

\section{Lectures:}

A variety of instructional lectures were scheduled (one or two daily, Monday-Friday) to directly address several of the camp educational objectives. (Camp objectives were not explicitly stated to participants.) 30-minute lectures were delivered by full or adjunct members of the Bioengineering Department. Faculty were encouraged to use real world examples based on their own research when possible. Lectures with the following titles were presented:

What does a Bioengineer do?

How does a Bioengineer approach a problem?

How does a Bioengineer design an experiment?

Why become a Bioengineer?

What is a Bio-entrepenuer?

How does a Bioengineer give an effective scientific presentation?

What schooling is required to become a Bioengineer? 
Tours:

Each day a specific tour was arranged for all participants. Tours were scheduled of laboratories in the local biomedical industry, and individual engineering faculty on campus. At the university, participants visited a virtual reality lab, an electronics manufacturing cleanroom, the Research Resource lab (confocal microscope, electron microscope etc.), a gene sequencing facility and the medical center. Off-campus, participants were given guided tours of a hip-implant manufacturing company and a medical museum.

\section{Laboratory Modules:}

We designed the heart of the summer camp experience to be a hands-on bioengineering laboratory research experience. Students were expected to perform scientifically rigorous experiments in one or more of several chosen bioengineering disciplines. Teachers were encouraged to participate, but were given the flexibility to move from laboratory to laboratory to watch the learning process in action. Laboratory topics were matched with the research specialty of participating faculty. Students (and teachers) were given lecture and laboratory instruction in their chosen area (see below), usually in the form of small group lectures within the laboratory spaces. Students worked individually, or in small groups of 2-3 within each laboratory module. University undergraduate and graduate Bioengineering students were employed as assistants in the labs, making the instructor to student ratio roughly 1:5. Experiments were conducted in each laboratory module and students were required to $\log$ and tabulate results. Students used the results to form the basis of a Power-point oral presentation given during a 'student symposium' on the last day of camp. In CY2 and CY3, this was attended by family members (and was called 'Family Day'). The laboratory modules were as follows:

1) Bio-robotics

2) Bioinformatics

3) Cell and Tissue Engineering

4) Recording Physiological Signals

5) Biomedical Imaging

\section{1) Bio-robotics}

Lego Mindstorms Robotics Kit were employed to allow students to build robots that demonstrated principles of biological behavior. As an example, a brief lecture on cockroach sensing and locomotion was given. Students were then paired and with minimal additional instructions, asked to build an autonomous robot using the cockroach as a design guide. Students could employ any of the available Mindstorm features. Design efficacy was tested via a classroom competition. Each autonomous vehicle was timed as it navigated a pre-made obstacle course. 


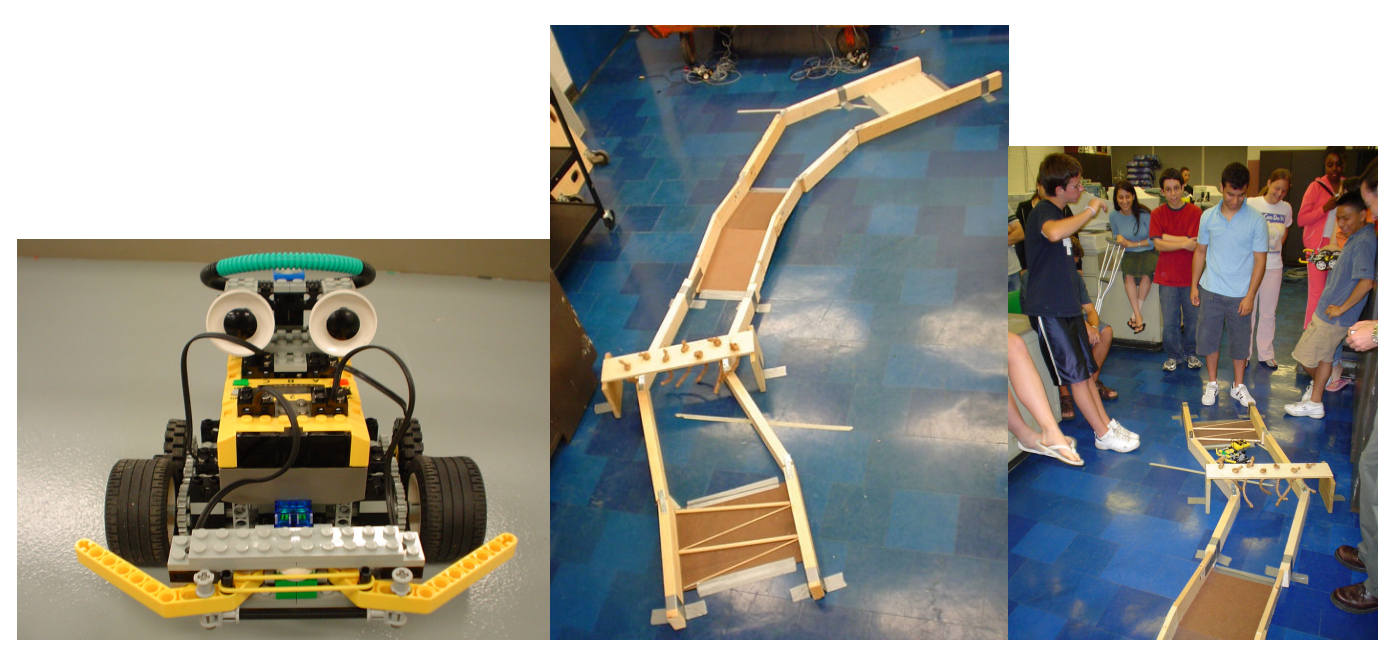

Figure 1: Left: a student-designed and built 'bio-robotic cockroach'. Center: The $15 \mathrm{ft}$. obstacle course included inclines, declines, curves and vertical rope obstacles. Right: A typical 'run' of a student vehicle through the course.

\section{2) Bioinformatics}

In this module, microarray technology was used to comparatively analyze genomewide patterns of mRNA expression as relates to cancer diagnosis. Lectures were used to emphasize the massive amounts of data inherent in these types of assessments. Students learned to use data mining tools to analyze data sets from a microarray experiment designed to diagnose leukemia cancer subtypes. Students were taught basic knowledge of the molecular biology database, Genebank and then used software packages to analyze and visualize results.

\section{3) Cell and Tissue Engineering}

Students performed experiments to create a simple model for skin-equivalent tissue. First, a 3D scaffold was constructed using collagen, a natural protein found in abundance. Collagen concentration was varied and its effects on the mechanicas of the scaffold structures determined. Second, human fibroblasts, connective tissue cells, were seeded into the 3D collagen scaffold to create a 'skin-like tissue'. The profound effect of cell density and shrinking were studied. Using the advanced imaging technique of confocal microscopy, the $3 \mathrm{D}$ cell distribution was visualized.

\section{4) Recording physiological signals}

In this module students employed rack-mounted instrumentation amplifiers to measure their own electrocardiograms (ECG) or electromyograms (EMG.) Signals were digitized, viewed and analyzed using a digital oscilloscope program and an A/D system. Students first received introductory lectures on the physiological sources of the ECG and EMG and the engineering aspects of signal recording and digitization. Student/teacher ECGs and EMGs 
were recorded and analyzed for a variety of experimental conditions (at rest, following exercise, etc.). Group results were pooled to emphasize and study concepts such as mean and standard deviation.

\section{5) Medical Imaging Imaging is playing an} increasingly important role in biological science and in medicine.

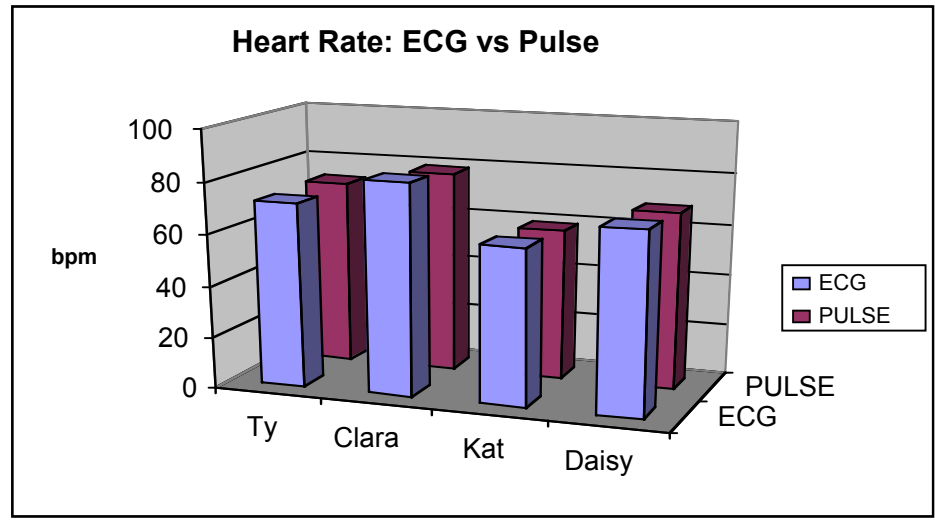

In this project students were introduced to the basic types of medical imaging (x-ray, CT, nuclear medicine, ultrasound, MRI). The mechanism of interaction for each form of energy with the human body was discussed as relates to image resolution and contrast. The potential medical applications of biomedical imaging and the safety risks involved were also described. A basic introduction text was provided to all students (Wolbarst). The student/teacher groups toured the university medical imaging facilities (x-ray/CT, Nuclear, Ultrasound, MRI) to learn about setting up, acquiring, and analyzing medical images. Finally, the students were asked to develop an imaging experiment using either a chicken egg at different stages of development or flower seeds.

\section{Feedback}

Participating students and science teachers were asked to judge a number of camp features by returning a survey. Each topic area was ranked on a scale from 1 to 5 or 1 to 10 depending on year. The survey was given on the first and last day of the camp in CY3 only. The same survey was given in CY2 as CY3, but only on the last day of camp. In CY1, a different survey was given on the last day of camp. In addition, participants were asked to include written comments, negative or positive.

\section{Results}

A week-long summer day camp was conducted for 3 consecutive years in order to increase bioengineering as a discipline among local 9-12 high school students. In CY1, 15 students attended. In CY2, 37 students and 5 teachers attended. For CY3, 17 students and 4 teachers attended. The camp was advertised via mailings to all high school science departments in the extended metropolitan area.

\section{Surveys}

Overall, based on informal discussions with the students and teachers and based on participant surveys (both scaled and written comments) there was a general sense of satisfaction and success with the program. Table I shows post-camp responses for the unique CY1 survey, ranked on a 1-5 scale. University laboratory demonstrations, the university medical center tour and the laboratory mentors (both university faculty and students) received the three highest average ratings $(4.47,4.42$ and 4.41$)$. These sentiments were echoed in the additional comments section supplied in writing on each survey. Lowest average scores were given for the off-campus activities that included a museum tour and a tour of a local biomedical engineering industry site (3.00 and 3.00). 


\begin{tabular}{|c|c|c|c|c|c|c|}
\hline Scale of 1 to 5 (5=best) & 1 & 2 & 3 & 4 & 5 & MEAN \\
\hline Lectures & & & 4 & 7 & 6 & 4.11 \\
\hline Laboratory Demonstrations & & & 2 & 5 & 10 & 4.47 \\
\hline Laboratory Projects & & & 4 & 5 & 8 & 4.23 \\
\hline University Laboratory tours & 2 & 1 & 6 & 4 & 1 & 3.35 \\
\hline University Medical Center tours & & & 2 & 4 & 8 & 4.42 \\
\hline Museum tour & 2 & 1 & 3 & 1 & 2 & 3.00 \\
\hline Industry tour & 3 & 1 & 6 & 1 & 3 & 3.00 \\
\hline Lunches & & 1 & 8 & 1 & 6 & 3.75 \\
\hline Laboratory mentors & & 1 & 2 & 3 & 11 & 4.41 \\
\hline
\end{tabular}

TABLE I: Score distribution of student post-camp results from CY1.

In CY2, the survey questions were changed and pre-camp responses were not obtained. In CY3, the same questions were used and presented both before and after the camp to determine if the camp had an impact on the responses. Table II shows post-camp responses for CY2 and pre and post-camp responses for CY3. Notably, the means for the post-camp questions were remarkably consistent between CY2 and CY3. In CY3, four of the nine questions showed a statistically significant increase following the week-long session $(\mathrm{P}<0.05$, Student's t-test for paired samples, one-tailed). Questions regarding 'familiarity with bioengineering', and those pertaining to job and college opportunities within bioengineering all had a statistically significant increase in mean score. Neither student interest in our particular university, nor the choice of community college vs. a 4-year university were significantly altered over the course of the week. 


\begin{tabular}{|l|c|c|c|c|}
\hline \multicolumn{1}{|c|}{ QUESTION } & Camp Year 2 & \multicolumn{3}{|c|}{ Camp Year 3 } \\
\hline $\begin{array}{l}\text { Right now, how familiar } \\
\text { are you with the field of } \\
\text { Bioengineering? }\end{array}$ & 7.27 & 4.33 & 7.08 & $+2.75^{*}$ \\
\hline $\begin{array}{l}\text { How familiar are you with } \\
\text { possible job opportunities } \\
\text { in Bioengineering? }\end{array}$ & 7.40 & 4.08 & 7.17 & $+3.08^{*}$ \\
\hline $\begin{array}{l}\text { Right now, how likely is it } \\
\text { that you will pursue a } \\
\text { career in Bioengineering? }\end{array}$ & 5.07 & 4.75 & 5.92 & $+1.17^{*}$ \\
\hline $\begin{array}{l}\text { How likely is it that you } \\
\text { will attend community } \\
\text { college? }\end{array}$ & 1.47 & 2.08 & 2.25 & +0.17 \\
\hline $\begin{array}{l}\text { How likely is it that you } \\
\text { will attend a 4-year } \\
\text { university? }\end{array}$ & 9.53 & 9.29 & 9.21 & -0.08 \\
\hline $\begin{array}{l}\text { Right now, how likely is it } \\
\text { that you will pursue a } \\
\text { college major in } \\
\text { Bioengineering? }\end{array}$ & 5.27 & 5.08 & 5.71 & $+0.63 *$ \\
\hline $\begin{array}{l}\text { Would you attend college } \\
\text { at this university? }\end{array}$ & 5.67 & 5.75 & 5.38 & -0.38 \\
\hline $\begin{array}{l}\text { Would you attend this } \\
\text { university to study } \\
\text { Bioengineering? }\end{array}$ & 4.73 & 4.88 & 5.38 & +0.50 \\
\hline $\begin{array}{l}\text { Would you attend another } \\
\text { college to study } \\
\text { Bioengineering? }\end{array}$ & 5.47 & 5.29 & 5.88 & +0.58 \\
\hline
\end{tabular}

TABLE II: Pre and post-camp mean scores in response to assessment questions (on a 1-10 scale). $\Delta$ represents the difference between the means. A ' $*$ ' in this column indicates statistically significant increases between pre and post answers (paired t-test, $\mathrm{p}<0.05$ ).

\section{Discussion}

A summer bioengineering camp was devised and conducted as a means of increasing 'visibility' of bioengineering for local high school students and science teachers. This report details data collected from student attendees of the camp. Responses were collected from the majority of students who were present at each day of the camp. Due to low sample size, teacher response data is considered anecdotal and not presented.

The camp appeared to meet the number one goal of organizers by increasing student awareness of bioengineering as a topic area. The student surveys revealed statistically significant mean increases for questions related to an increase in 'familiarity' of 
bioengineering or the job opportunities in bioengineering. This is not surprising after the weeklong intensive experience. The roughly 3-point increase in these areas is not an indicator of whether or not the student 'enjoyed' the increased familiarity or job knowledge, it simply reveals that knowledge was gained. A more telling indicator is whether or not students, armed with the new knowledge considered changing their career or college plans. Evidence for this type of influence was present but much less convincing in the slim, but significant +0.63 and +1.17 mean increase in response to the questions of 1 ) whether or not bioengineering would be chosen as a college major or 2) whether or not students would pursue a career in bioengineering. Because long-term follow-up was impractical, it is not known whether or not these means represent an immediate post-camp 'bump' or are indicative of longer term change. Anecdotally, it is notable that for each year the camp was held, at least one student and up to four (CY1) who attended the camp later became registered undergraduates in the bioengineering program at our university. In CY2 and CY3 sophomores and junior students were recruited with the intent of students being able to better prepare (choose appropriate classes) for a college career in bioengineering. We also wanted students who had not yet applied or committed to other universities, in the hopes of raising the probability that they would consider our university. Staff limitations impede our efforts to judge the local effects of accepting only juniors or sophomores over seniors.

Changes were not seen regarding student intent to study at a 4-year college vs. a community college, nor were there changes in the intent of students to study bioengineering at our university or any other. For the former, we naively presumed passive exposure to the university environment would cause some changes in these areas. However, the mean of 9.53 for this question in CY2 suggests that this was not an area that needed improvement. At any rate, without actively addressing these issues via lectures or laboratory sessions, no significant changes in these attitudes were recorded. Interestingly, the means for post-camp CY2 and CY3 were very similar overall, likely reflecting a consistent pool of students. For instance, the highest mean of 9.53 in CY2 was matched with a 9.21 in CY3. The lowest mean of 1.47 in CY2 (for intent to attend a community college) was a 2.25 for CY3. Thus, the camp consistently attracted 4-year university-bound students.

Students seemed to especially welcome the challenge of creating the Power Point presentation for the last day. This goal directed activity (implemented in CY2 and CY3) was an essential motivating factor in advancing knowledge in the laboratory. Good faith efforts to collect presentable data were combined with an overall desire to create aesthetically pleasing presentations. Several students worked on the presentation at home in the evening.

The intense focus of the day camp seemed to forge a unique social environment. Students from urban and suburban schools co-mingled under the common interest of science. Faculty and students intermixed before lectures, while walking to and from the lab sites and during the slower periods of the laboratory work. In general, the mood of most people involved could be anecdotally classified as upbeat. One reason could be the lack of competing time resources during the summer allowed for consistent focus on an exciting topic area. 
For the university faculty involved, this experience came at a cost. Many faculty participated directly with volunteer graduate student assistants. Even those who did not participate in laboratory sessions lost the research output of their students who did volunteer. Faculty preparation time was considerable, anecdotal reports of about 20 hours preparatory time before the week began were typical. Organizing student applications and creating mailings was a large organizational task for an already overworked office staff. The first year of the camp was generously supported via a Whitaker grant, but later offerings were completely subsidized by the department/faculty members. To offset financial losses and subsidize laboratory costs, a $\$ 100$ camp fee was implemented in years 2 and 3 . Students were waived from the fee with a letter from parents.

The drain on faculty energy without any other form of remuneration has proven too much for the continued offering of the camp as described. Although most faculty reported it to be a 'worthwhile' endeavor, the camp could not survive the host of other faculty commitments (among them participation in the NSF's Research Experience for Undergraduates program) and was not held this past summer. The overall results suggest that the camp is indeed a useful vehicle for the attendees. There is a general feeling among the camp faculty and teachers that an extended yearly offering of the camp would in the long-run be an asset to students, teachers and for the long-term 'brand-recognition' of our university within the local college/university market. However, to succeed, such a program needs extensive administrative support. This support must come in terms of recognition of the time commitment incumbent on all participating faculty. The administration/college/department must be willing to provide lab supplies, faculty summer salary, graduate student assistant salaries, and extensive clerical and planning support. Decisions on whether to implement such a program must obviously be made on a case-by-case basis. With essentials in place however, a bioengineering camp could be offered yearly and become a fixture on the 9-12 academic scene. We suggest that similar programs could easily be implemented in any of the other engineering disciplines.

\section{References}

Malgorzata S. Zywno, Member, IEEE, Kimberley A. Gilbride, Peter D. Hiscocks, Judith K. Waalen, and Diane C. Kennedy, Member, IEEE, Attracting Women into Engineering: A Case Study. IEEE TRANSACTIONS ON EDUCATION, VOL. 42, NO. 4, Nov. 1999.

McCullough, C.L.; Crull, M.; Thomas, D. Adventures in Engineering: a unique program to attract under-represented groups to engineering, IEEE Transactions on Education Volume: 37 Issue: 1 , Feb. 1994.

Jaffe-Ruiz M, Stokes SA, Thomas B. Nursing summer camp: a recruitment experience for high school students. J Nurs Educ. 1989 Sep;28(7):322-3.

Openshaw S, Fleisher A, Ljunggren C. Teaching biomedical applications to secondary 
students. Biomed Sci Instrum. 1999;35:69-72.

Wolbarst, A.B. Looking Within: How x-ray, CT, MRI, Ultrasound and Other Medical Images Are Created, and How They Help Physicians Save Lives. University of California Press, 1999. 